\title{
La retórica de lo extremo en la ultraderecha chilena*
}

\author{
Juan Antonio González de Requena Farré**
}

Recibido: 18 de enero de 2016

Evaluado: 10 de marzo de 2016

Aceptado: 1 de abril de 2016

\section{Resumen}

Este artículo pretende caracterizar la ideología de la extrema derecha chilena a través de su historia. Se realizó un análisis del discurso de los manifiestos y declaraciones de principios de cuatro formaciones de ultraderecha de distintos momentos de la historia de Chile: el Movimiento Nacional Socialista, el Movimiento Revolucionario Nacional Sindicalista, el Frente Nacionalista Patria y Libertad, así como Patria Nueva Sociedad. El enfoque retórico de la ideología ultraderechista permite reconstruir las autodescripciones ideológicas, las articulaciones del autoritarismo, los marcos figurativos y las principales construcciones argumentativas de la extrema derecha chilena.

Palabras clave: Extrema derecha, nacionalismo, autoritarismo, discurso ideológico. 


\section{The rhetoric of the extreme in the Chilean far right}

\section{Abstract}

This article aims to characterize the ideology of the Chilean extreme right throughout its history. A discourse analysis was made of the manifestos and declarations of principles of four far right-wing formations from different moments in Chile's history: Movimiento Nacional Socialista, Movimiento Revolucionario Nacional Sindicalista, Frente Nacionalista Patria y Libertad and Patria Nueva Sociedad. The rhetorical approach to far right ideology allows us to reconstruct ideological self-descriptions, articulations of authoritarianism, figurative frameworks and the main argumentative constructions of the extreme Chilean right.

Keywords: extreme right, nationalism, authoritarianism, ideological discourse. 


\section{A retórica do extremo na ultra-direita chilena}

\section{Recebido: 18 de janeiro de 2016 \\ Avaliado: 10 de março de 2016}

Aceito: 1 de april de 2016

\section{RESUMO}

Este artigo pretende caracterizar a ideologia da extrema-direita chilena através da sua história. Realizou-se uma análise do discurso dos manifestos e declarações de princípios de quatro formações de ultradireita de diferentes momentos da história do Chile: o Movimento Nacional Socialista, o Movimento Revolucionário Nacional Sindicalista, a Frente Nacionalista Pátria e Liberdade, assim como Pátria Nova Sociedade. O enfoque retórico da ideologia de ultradireita permite reconstruir as autodescrições ideológicas, as articulações do autoritarismo, os marcos figurativos e as principais construções argumentativas da extrema-direita chilena.

Palavras-chave: extrema direita, nacionalismo, autoritarismo, discurso ideológico. 
En una perspectiva politológica, podríamos considerar - con Norberto Bobbio- que el aspecto extremista de una posición política radica en la apuesta estratégica por la exaltación de la violencia, la temeridad heroica, la resolución autoritaria y la impugnación de los marcos de legitimación de la democracia moderna (la soberanía popular y la razón pública, así como las libertades iguales y garantías personales asociadas al Estado de derecho), sobre el fondo de cierta denegación reaccionaria del legado de la Ilustración (Bobbio, 1996, pp. 76-82 y 161163). Desde ese punto de vista, podríamos considerar que la extrema derecha contemporánea no solo ha naturalizado la división de lo social y la distribución desigual de los recursos y oportunidades sociales, sino que además recurre al discurso antisistema, a cierta retórica revolucionaria o a la justificación del empleo instrumental de la violencia política, como herramientas para contraatacar las reivindicaciones igualitarias asociadas a la revolución democrática moderna, disciplinar orgánicamente lo social, para la dominación autoritaria y el control del orden, así como para la inmunización comunitaria o la exclusión identitaria.

Ciertamente, no existe un perfil homogéneo de la extrema derecha política. Los fascismos del siglo $\mathrm{XX}$ no solo se caracterizaron negativamente por su rechazo del parlamentarismo liberal y del materialismo marxista. Según Michael Mann (2004), los movimientos fascistas también se han definido positivamente por su proyecto nacionalista y estatista, en procura de cierta trascendencia de los conflictos sociales en un nuevo orden armónico; asimismo, se distinguen por el recurso a la exclusión identitaria, la agresión y la purificación étnica o política, así como por una disciplina y forma de organización paramilitares. Por otra parte, los partidos de extrema derecha de las últimas décadas del siglo XX no se caracterizan por un único rasgo como la hostilidad al progreso o la posición antidemocrática o anticomunista, sino que exhiben también aspectos como el nacionalismo extremo, el etnocentrismo, la xenofobia, el apego a la ley y el orden, la demanda de liderazgos autoritarios, entre otros. Betz (1993) describió a los partidos de extrema derecha surgidos en la década de los ochenta como formaciones radicales, ya que rechazan el sistema establecido cultural y político establecido (el Estado del bienestar, la burocracia y los partidos políticos), a la vez que apelan a la iniciativa y logro individuales en el libre juego del mercado, así como a la reducción de la intervención estatal. Además, serían partidos de derecha por su rechazo de la igualdad, su oposición a la integración social de los grupos excluidos y su posición xenófoba o abiertamente racista. Por último, se trataría de formaciones populistas, que instrumentalizan los temores y sentimientos del hombre común o el descontento popular y consagran el sentido común del pueblo.

Según Mudde (2000), la mayoría de las caracterizaciones del extremismo de derecha contemporáneo incluyen rasgos como el nacionalismo, el racismo, la xenofobia, la posición antidemocrática y la valoración de un Estado fuerte, de manera que podríamos reconocer un núcleo ideológico central de la extrema derecha actual: al nacionalismo y a la aspiración a la congruencia político-cultural mediante la homogeneización interna de la sociedad y la expatriación de extranjeros, se suma la xenofobia como visión el 
mundo que considera lo ajeno a lo convencional o lo nacional como algo negativo y amenazador $\mathrm{y}$, por tanto, como un enemigo interno o externo. De la combinación de nacionalismo y xenofobia, se siguen políticas socioeconómicas en beneficio exclusivo del propio pueblo o de los connacionales (cierto chauvinismo del bienestar) y políticas externas proteccionistas y de afirmación de la soberanía nacional de fuerzas exteriores. Por último, se da un apego a la ley y el orden, o sea al mantenimiento de un sistema legal estricto y la aplicación rigurosa de las reglas (Mudde, 2000, p. 177). En suma, pese a la diferencia de designaciones de la extrema derecha contemporánea (derecha populista radical, populismo xenófobo, nacionalismo populista o derecha radical), cabe reconocer algunos rasgos característicos de su marco ideológico: en primer lugar, la perspectiva de cierto nativismo, la noción exclusivista y etnonacionalista de la ciudadanía y su posición antiinmigración; en segundo lugar, la retórica populista y antiestablishment, que divide a la sociedad entre el pueblo y la élite corrupta; por último, el autoritarismo, el apego a la ley y el orden, el conformismo y la sumisión a los valores tradicionales (Muis e Immerzeel, 2016).

Por supuesto, existen variantes locales en el despliegue de los movimientos de extrema derecha contemporáneos, por ello resulta preciso estudiar específicamente las tendencias históricas y constelaciones ideológicas de las diferentes ultraderechas en cada realidad política; por ejemplo, en Chile. En las reconstrucciones históricas y politológicas de la derecha chilena, no siempre se ha considerado el papel que han desempeñado las posiciones de extrema derecha en el siglo XX. En sus reconocidos análisis históricos,
Sofía Correa Sutil ha privilegiado la descripción de distintas oleadas de la derecha chilena en el siglo $X X$, enfatizando el protagonismo de las élites organizadas, así como la flexibilidad, la capacidad de negociación y la cooptación que caracterizaron a la derecha tradicional, esto es, a los partidos conservador y liberal. En la reconstrucción histórica de Correa, el estilo político flexible y negociador de la derecha tradicional dio paso a posiciones populistas y nacionalistas (como las del Partido Conservador Socialcristiano o el Partido Nacional) que intentaban canalizar o contener la emergencia y creciente protagonismo de nuevas fuerzas sociales y sectores populares en la realidad económica y política del siglo XX. En el escenario político posterior a la dictadura pinochetista, Correa identifica la irrupción de una nueva derecha en que confluyen posiciones gremialistas y neoliberales; semejante constelación ideológica habría sustentado el diseño de la institucionalidad y del orden económico-social que dieron forma al modelo político aún vigente en Chile (Correa, 1989; 2005). En tanto que historia de la derecha de las élites tradicionales y reconstrucción de la conformación del actual modelo político y económico chileno, los trabajos de Correa no dan cuenta de los movimientos de extrema derecha extraparlamentarios ni del influjo ideológico de la ultraderecha en la constelación política de la derecha en Chile.

Otras reconstrucciones politológicas de la derecha chilena e historias intelectuales del pensamiento conservador en Chile también llevan a cabo esta desconexión entre la derecha y la extrema derecha (Cristi y Ruiz, 1992; Scully, 1996). Por otro lado, hallamos reconstrucciones de la historia política de 
formaciones de ultraderecha como el movimiento nacionalsocialista chileno, que acentúan el carácter singular y cada vez más residual del fascismo de este país (Etchepare y Stewart, 1995). No obstante, encontramos trabajos que exploran el núcleo anticomunista, antiliberal, nacionalista y autoritario de extrema derecha, presente en la familia política derechista, en sus vertientes ultracatólica, gremialista o neoliberal (Bohoslavsky, 2012). Incluso, hay obras que califican como partidos de ultraderecha a los partidos más protagónicos de la derecha chilena actual, la Unión Demócrata Independiente y Renovación Nacional, por considerar que defienden el legado de la dictadura militar pinochetista y el encuadramiento de la sociedad bajo el orden moral de la civilización cristiana occidental (Rodríguez Araujo, 2004, p. 80). ¿Resulta, pues, solamente marginal y residual el discurso de la ultraderecha en la conformación del lenguaje de la derecha chilena, o es decisivo y constitutivo, al punto de instalarse en el núcleo del modelo institucional y socioeconómico del Chile actual?

Al realizar un análisis del discurso de los manifiestos y declaraciones de principios de algunos movimientos representativos de la extrema derecha chilena, se pueden reconstruir los principales significantes movilizadores, oposiciones nocionales, marcos figurativos y estrategias argumentativas presentes en la constelación ideológica ultraderechista. Además, cabe reconocer las deudas simbólicas entre esa ultraderecha considerada residual o marginal y, por otra parte, los lenguajes hegemónicos de la derecha chilena contemporánea, que frecuentemente se han investido bajo marcos retóricos e ideológicos de la extrema derecha.
Precisamente, este estudio lleva a cabo un análisis retórico de discurso de un corpus constituido por los manifiestos o declaraciones de principios de cuatro formaciones de la extrema derecha chilena: en primer lugar, el discurso de Jorge González von Marées que presenta las declaraciones fundamentales, plan de acción, organización y programa del Movimiento Nacional-Socialista de Chile (1932); en segundo lugar, las "Proposiciones políticas a las Comunidades de la Nación" (1969) y los contenidos "Quiénes somos", "Qué hacemos", "Qué queremos" y "Preguntas Frecuentes", alojados en la página web del Movimiento Revolucionario Nacional Sindicalista (la formación con más historia de la ultraderecha chilena, entre 1952 y la actualidad); en tercer lugar, el Manifiesto Nacionalista del Frente Patria y Libertad, publicado por Pablo Rodríguez Grez en 1971; por último, el texto Ciento once Conceptos para comprender el socialismo nacional, publicado digitalmente por Alexis López Tapia, el fundador de la formación Patria Nueva y Sociedad, que operó entre los años 1999 y 2010.

\section{Autodescripciones IDEOLÓGICAS}

En el marco del Análisis crítico del discurso propuesto por Van Dijk (2006), los discursos reproducen ideologías que conciernen a esquemas fundamentales para categorizar la pertenencia grupal y definir cierta identidad social, a través de descripciones autoidentitarias de quienes somos, lo que hacemos, nuestras metas, intereses y valores, nuestros recursos y las relaciones posicionales con otros grupos, generalmente mediante la representación discursiva polarizada del endogrupo y el exogrupo. En los 
textos de la ultraderecha analizados, encontramos autodescripciones discursivas de las distintas formaciones y sus propósitos, así como caracterizaciones antagónicas del principal enemigo.

En el caso del nacionalsocialismo de los años treinta, hay un distanciamiento con respecto a la caracterización tradicional de las fuerzas políticas como partidos, y se apuesta por la autopresentación del colectivo como un movimiento; semejante sujeto político enuncia su posición en tanto que representante de Chile, de cierta fuerza (nacional, política, espiritual y moral) e, incluso, de la raza y el orgullo de raza. Concretamente, el discurso de González von Marées describe al nacismo como un movimiento nacional, un movimiento popular, un movimiento socialista (que antepone la función social), una fuerza moral y racial, pero también una fuerza física (que no teme contratacar con violencia). Pese a no ser declarada en el texto, cabe reconocer una remisión interdiscursiva del nacionalsocialismo chileno a las doctrinas del fascismo italiano; concretamente, comparten la perspectiva dinámica de la fuerza y de la actividad vital, la concepción orgánica del mundo, la visión heroica del pasado histórico, la consagración del Estado, la crítica de la democracia liberal y la apelación a la disciplina (Mussolini, 1937/2015). También se atisba cierto solapamiento con el discurso expresado en los principios originarios del Partido Nacional Socialista Obrero Alemán: aunque no se da el énfasis racial y territorial del nazismo alemán, el nacionalsocialismo chileno reproduce la condena de la especulación plutocrática, el llamado al deber productivo y la concepción orgánica de la autoridad estatal (NSDAP, 1920/2015). Respecto al proyecto y horizonte de cumplimiento de la propuesta del Movimiento Nacional Socialista, se plantea cierta apuesta por realizar una concepción socialista del Estado como "motor e inspirador supremo de la vida nacional en sus múltiples manifestaciones, ya sean estas administrativas o económicas, intelectuales o afectivas" (1932, p.19). Por último, el antagonista del Movimiento Nacional Socialista resulta descrito como la oligarquía plutocrática, el régimen democrático-parlamentario, el liberalismo económico y político, la mentalidad democrático-liberal, el comunismo soviético y, en general, el viejo sistema de partidos políticos.

El Movimiento Revolucionario Nacional Sindicalista (vigente desde 1952 hasta el presente) también marca distancia con el léxico de los partidos políticos tradicionales a través de la autodescripción del grupo como movimiento, como una doctrina, una moral o un estilo, incluso, se atribuye un ser revolucionario, que lucha por la instauración de un Orden Nuevo. En la enunciación del discurso Nacional Sindicalista, el Movimiento dice representar a la Comunidad Nacional, en tanto que comunidad de destino en lo universal, la cual integra políticamente las distintas funciones orgánicas de la convivencia humana y los cuerpos comunitarios que las realizan (Familia y Comunidad Social, Sindicato y Comunidad Económica, Comunidad Universitaria, Comunidad Religiosa, Fuerza Armada y Comunidad Armada). En sus textos, el Movimiento señala explícitamente hablar por la escuela corporativa y recoger la herencia de la tradición nacionalsindicalista española de Ramiro Ledesma y José Antonio Primo de Rivera, así como del pensamiento social católico y el tradicionalismo hispánico. En 
efecto, del Programa de la Falange Española se recoge todo el discurso de la nación como unidad de destino en lo universal, la visión valórica del ser humano, el repudio al sistema capitalista, el concepto orgánico de la producción social, la concepción nacionalsindicalista del sindicato único, así como la apelación a un estilo ético revolucionario (Falange Española de las J.O.N.S., 1934). Por otra parte, el Movimiento se desmarca del nazismo alemán, por no compartir su teoría de la superioridad racial ni el principio de jefatura vertical; también se distancia del nacionalismo chileno más combativo, por considerar que carece de proyecto político. El proyecto del Movimiento Revolucionario Nacional Sindicalista tiene como meta la institucionalización del convivir comunitario en un Estado de Comunidad Nacional, pero también la realización de la unidad de los pueblos de Iberoamérica en una Comunidad Iberoamericana de Naciones. En cuanto a los términos antagónicos de la propuesta Nacional Sindicalista, se señalan la plutocracia, el liberalismo y el socialismo marxista, la democracia liberal, el reformismo y el imperialismo; con un posicionamiento abiertamente revolucionario, el Movimiento se autoconcibe como una “Oposición Extraparlamentaria y Anti-partidista" (1969, proposición 44).

Respecto al Frente Nacionalista Patria y Libertad de comienzos de los setenta, no existe renuencia a la autodescripción como una ideología política, el nacionalismo, que pretendería expresar inherente y transparentemente los intereses espontáneos del pueblo chileno, o bien de un nosotros inscrito como nuestro pueblo o Chile, bajo la única inspiración de la Historia de Chile y el amor a la Patria. El Frente Patria y Libertad considera, pues, impropio el adoptar ideologías extranjeras y no se reconoce como una formación nacista, ultraderechista o totalitaria. En todo caso, pese a su escrupulosa afirmación de autoctonía, el texto de Patria y Libertad remite interdiscursivamente a la doctrina de la seguridad nacional propagada por Estados Unidos en Latinoamérica tras la revolución cubana, y refleja nítidamente su anticomunismo beligerante; también recoge el discurso autoritario y desarrollista del franquismo español, así como su defensa corporativista de la representación política orgánica, la apuesta por una producción social sostenida en la propiedad privada y el deber del trabajo, o bien la consagración y estímulo de la iniciativa privada (Ley de principios del movimiento nacional de 1958, 1967). El proyecto del Frente Nacionalista apunta a concretar un Estado Nacionalista Chileno: se trata de lograr un Estado Integrador, que unifique orgánica y armónicamente a la comunidad chilena; un gobierno autoritario, regido por la ley y el orden; una población comprometida con la responsabilidad colectiva y encuadrada por la disciplina social; un programa juvenil que convoque a las nuevas generaciones; una empresa integrada, que involucre a los trabajadores en la codirección de la producción; finalmente, una democracia funcional y corporativa, en la cual se haga efectiva la participación real de los gremios y las corporaciones. Para lograr este propósito de un Estado Nacionalista Chileno, el Frente Patria y Libertad no tiene reparos en luchar por la conquista del poder tanto mediante la colaboración electoral con los partidos democráticos, sin pactos ni alianzas, como mediante la lucha revolucionaria, la escalada armada y el apoyo a un eventual pronunciamiento militar. En el discurso del Frente Nacionalista 
Patria y Libertad se hace más explícito el anticomunismo y el antagonismo al marxismo, cuestionado como una ideología totalitaria, foránea y destructora de los valores de la civilización cristiana. También se esbozan como antagonistas la demagogia, el sistema político parlamentario imperante, los ideologismos intrascendentes, la burocracia estatal, la manipulación de la juventud, la empresa capitalista, el Estado paternalista, la democracia liberal inorgánica, o bien el sectarismo y divisionismo de los partidos políticos tradicionales.

El discurso que la formación Patria Nueva y Sociedad sostuvo entre los años 1999 y 2010 se autocaracterizó como una Cosmovisión Socialista Nacional, que no asociaba el socialismo a un modelo económico o a una teoría política, sino a la expresión espiritual del altruismo vital y la reciprocidad natural de los intereses comunitarios, y vinculaba su concepción nacional a la pertenencia y preservación de la Comunidad del Pueblo, más que al nacionalismo. En ese sentido, Patria Nueva y Sociedad habla primariamente en nombre de la Comunidad del Pueblo, entendida como la expresión territorial, cultural, lingüística, tradicional e histórica de una población humana; adicionalmente, la cosmovisión Socialista Nacional se presenta como la verdad misma de la Naturaleza, de su sentido espiritual y su ecología de la mente, la manifestación de la diversidad cultural y biológica de los pueblos y razas humanas en el seno de la comunidad de vida planetaria. Por otra parte, Patria Nueva Sociedad interpela a los chilenos orgullosos de sus tradiciones, cultura y estirpe, sin distinción de situación socioeconómica. De modo implícito, en la cosmovisión de Patria Nueva Sociedad se reconoce la remisión interdiscursiva a la Nueva Derecha francesa de los años ochenta y noventa: comparte con ella el tono reflexivo metapolítico y la pretensión de hegemonía cultural; la crítica del progresismo, del proyecto de modernización desarrollista y del nuevo orden mundial surgido de la globalización; la combinación de una cosmología naturalista y del holismo ecológico con motivos comunitaristas y con cierta reivindicación pluralista de las identidades culturales y del derecho a la diferencia; el llamado a una democracia realmente participativa y centrada en la iniciativa popular; por último, una organización de la producción que, más allá del productivismo, la especulación financiera y el consumismo, se ponga al servicio de la vida, preserve lo local y asuma una escala humana (Benoist y Champetier, 2000). El proyecto de Patria Nueva Sociedad involucra la realización de un Estado Orgánico, bajo la premisa de que el Estado no es un fin en sí mismo, sino solo un medio artificial al servicio de la conservación, adaptación y expresión de la identidad nacional, cultural y natural de la Comunidad del Pueblo. En ese sentido, el Estado Orgánico está en constante proceso de adaptación a la voluntad de la Comunidad del Pueblo y no constituye una estructura institucional inmodificable sino un Estado óptimo y a escala humana, capaz de sostener la homeostasis social, de manera que la legalidad y el derecho solo obtienen legitimidad en la medida en que expresen la preservación de la justicia en la Comunidad del Pueblo. El proyecto político asociado a la cosmovisión Socialista Nacional involucra, además, el gobierno descentralizado, la jerarquización horizontal de las responsabilidades y la autoridad social, un modelo político corporativo, un ordenamiento gremialista de la producción, un 
sistema empresarial sinérgico basado en el trabajo y la propiedad, la subordinación del economía a la política social, así como una reestructuración del ámbito de la salud y la seguridad social, más allá de la lógica del mercado; en última instancia, proyecta un modelo de desarrollo ecológico que atienda a la sustentabilidad de la Naturaleza y promueva una nueva civilización planetaria "basada en las leyes trascendentes del Espíritu, de la Vida y de la Naturaleza" (concepto 110). Como antagonista, el discurso de Patria Nueva Sociedad sitúa al Nuevo Orden Mundial, con su modelo materialista y de mercado; pero también se expresa la oposición al capitalismo trasnacional, al marxismo, al igualitarismo liberal, la partitocracia, la oligocracia, los poderes fácticos, el individualismo materialista, el consumismo y el nihilismo.

\section{Articulaciones discursivas DEL AUTORITARISMO}

Desde los años cuarenta, la investigación social trató de explicar el auge del fascismo en Europa, a través del estudio empírico de la personalidad autoritaria; se trataba de aclarar la pauta ideológica y la constelación de convicciones que subyacen al antisemitismo, al potencial antidemocrático y a la adhesión a la propaganda fascista. En ese sentido, la investigación de Adorno, Frenkel-Brunswik, Levinson y Sanford (2006) sobre la personalidad autoritaria introdujo una Escala de Tendencias Antidemocráticas o de Fascismo Potencial (F) que medía variables como el convencionalismo, la sumisión autoritaria, la agresión autoritaria hacia quienes infringen las normas convencionales, la oposición a la subjetividad, la superstición y los estereotipos, la afirmación del poder y la dureza, la visión proyectiva del mundo como un lugar peligroso o la preocupación desmedida por la sexualidad (Adorno, Frenkel-Brunswik, Levinson y Sanford, 2006). A pesar de las críticas metodológicas que generó, la investigación sobre la personalidad autoritaria tuvo cierta continuidad en el tiempo. Así, en los años ochenta, Robert Altemeyer desarrolló una escala simplificada para dar cuenta del autoritarismo de derechas (RWA), que pretendía medir la covariación de tres grupos de actitudes: la sumisión autoritaria, esto es, un alto grado de adhesión a las autoridades; la agresión autoritaria, o sea, una marcada hostilidad contras aquellas personas cuestionan la legalidad y la autoridad; finalmente, el convencionalismo o la aceptación acrítica de las normas sociales, del orden vigente y de la autoridad establecida. Existe abundante investigación en psicología política que correlaciona los puntajes obtenidos en la Escala de Autoritarismo de Derecha con el racismo, el sexismo, el conservadurismo político, el apoyo a la pena de muerte, el patriotismo, el fundamentalismo religioso y el militarismo, entre otros aspectos (Altemeyer, 1993).

En la última década, se ha propuesto redefinir los tres aspectos del autoritarismo propuestos por Altemeyer (agresión autoritaria, sumisión autoritaria y convencionalismo) como dimensiones relativas a actitudes sociales o ideológicas, más que como rasgos de personalidad: el autoritarismo correspondería a actitudes que favorecen el control social punitivo estricto y severo, por contraposición a la indulgencia con la infracción de las normas; el conservadurismo define aquellas actitudes de obsecuencia 
con las autoridades e instituciones sociales, a diferencia de las actitudes de oposición; por último, el tradicionalismo se entiende como las actitudes que fomentan la moralidad, normas sociales o valores tradicionales, frente a la moralidad, normas y valores modernos, liberales y seculares. En esas actitudes está en juego el apoyo u oposición a subordinar la libertad individual y la autonomía personal al colectivo y su autoridad; esto es, si se privilegia la autonomía individual y la autoexpresión, o bien la seguridad colectiva y la cohesión grupal (Duckitt, Bizumic, Krauss y Heled, 2010).

En la investigación contemporánea en psicología política ha ganado terreno la idea de que, además del autoritarismo, resulta preciso considerar otro constructo que subyace a las actitudes de derecha, el prejuicio etnocéntrico, el racismo o el clasismo: la orientación a la dominación social (Sidanius y Pratto, 1999). Desde esa perspectiva, la aceptación de ideologías que legitiman la desigualdad respondería al deseo general de las personas por la dominación social, esto es, a la orientación a la dominación social, que permite entender diferencias individuales en las actitudes y conductas socio-políticas tales como el favoritismo hacia el endogrupo o el involucramiento con papeles sociales asociados al grado jerárquico. Al alero de la teoría de la dominación social de Sidanius y Pratto, la Escala de Orientación a la Dominación Social (SDO) fue desarrollada precisamente para medir la predisposición de los individuos a mantener relaciones intergrupales jerárquicas y desiguales. En ese sentido, cabría pensar que las actitudes ideológicas derechistas se organizan en virtud de dos dimensiones aprehendidas respectivamente por los constructos del autoritarismo de derechas y la orientación a la dominación social, que se asocian a diferentes motivaciones, creencias y comportamientos socio-políticos. Concretamente, el autoritarismo de derechas expresaría una visión del mundo como un lugar peligroso, en contextos sociales amenazadores y con personalidades conformistas; por otro lado, la actitud ideológica caracterizada como orientación a la dominación social da cuenta de una visión del mundo como un ámbito de lucha competitiva, sobre el trasfondo de personalidades rígidas y contextos sociales de competencia o dominación grupal (Duckitt y Sibley, 2009).

En los manifiestos y declaraciones de principios analizados, cabe reconocer posicionamientos declarativos y enunciados valorativos que expresan explícitamente las actitudes asociadas al autoritarismo psicopolítico. En ese sentido, el tradicionalismo aparece abiertamente articulado en los propósitos de Movimiento Revolucionario Nacional Sindicalista, en la concepción de Patria Nueva Sociedad y, en menor medida, en el Frente Nacionalista Patria y Libertad. El Movimiento Revolucionario Nacional Sindicalista asume una vocación decididamente revolucionaria, crítica del reformismo y no confesional, pero considera que el Estado de Comunidad Nacional proyectado ha de erigirse como depositario de una tradición arraigada en la comunidad social del pueblo y en la historia, de modo que la apuesta revolucionaria no involucraría una impugnación de la trascendencia metafísica y religiosa. En el caso de Patria y Libertad, pese a que, desdeuna posición beligerante de vanguardia contrarrevolucionaria, se cuestionan los esquemas, corrientes y partidos políticos tradicionales, encontramos apelaciones "a la idiosincrasia 
de nuestro pueblo y a una larga tradición histórica que nos revela como libertarios, amantes del derecho y de la juridicidad" (1971, p. 32) y a "los valores esenciales de la civilización cristiana" (p. 5). Por lo que respecta a Patria Nueva y Sociedad, las tradiciones y costumbres históricas se consideran constitutivas de la identidad cultural y la expresión de la nacionalidad de la Comunidad del Pueblo, de manera que han de ser valoradas, respetadas y promovidas, en nombre de la preservación del equilibrio ecológico y sustentabilidad de las formas de vida. A diferencia de las otras formaciones de extrema derecha, el Movimiento Nacional Socialista de los años treinta se caracterizaba por una decidida inspiración revolucionaria, que se expresa en la constante invocación de lo nuevo de la situación: la nueva etapa, las nuevas aspiraciones y las nuevas fuerzas.

El conservadurismo, la obsecuencia con la autoridad y la sumisión autoritaria también se encuentran articulados en los manifiestos y declaraciones de propósitos de la extrema derecha chilena. El principio de autoridad se afirma explícitamente en los textos del Frente Patria y Libertad y en las concepciones de Patria Nueva Sociedad. En efecto, Patria y Libertad apuesta por un gobierno autoritario que restituya el principio de autoridad, sin el cual no habría orden, progreso, armonía social, justicia legal o democracia legítima, pues no se cumplirían y acatarían las normas ni se sancionarían las infracciones sin privilegios ni sectarismos. Por su parte, Patria Nueva Sociedad consagra la autoridad legítima que emana de la voluntad de la Comunidad del Pueblo y resulta representada por los mandatarios y la "vocación de servicio de los líderes" (concepto 56). En todo caso, se argumenta que semejante autoridad no implica sumisión, sino colaboración responsable. Del mismo modo, en los discursos del Movimiento Revolucionario Nacional Sindicalista y en Patria Nueva Sociedad, se hace presente la valoración de la jerarquía. No en vano, los nacionalsindicalistas consagran la jerarquía como expresión de la trascendencia humana que toma forma en culturas y derechos y deberes humanos, y se proponen crear cultura y reconocer la jerarquía para posibilitar la realización humana; al fin y al cabo, la jerarquía se perfila como un principio trascendente que "operando en función de valores, posibilita la integración, ordenación y dinamización del proceso histórico de un pueblo" (1969, proposición 3). Asimismo, Patria Nueva Sociedad defiende una estructuración del poder sociopolítico sustentada en "jerarquías horizontales y circulares, que reflejen la ordenación y flujo natural de la responsabilidad y la autoridad social" (2003, concepto 55); se trata de una valoración de la jerarquía que no asume los privilegios, sino que antepone la responsabilidad colectiva de los individuos con la Comunidad del Pueblo. La asunción de que el individuo ha de trabajar para el colectivo y subordinar sus intereses a los de la sociedad y a la función social aparece con fuerza en el discurso del Movimiento Nacional Socialista; al mismo tiempo que el nacismo chileno apela a la selección de personalidades fuertes y decididas, define su ética política en términos de disciplina, orden y renuncia individual en beneficio de la Comunidad del Pueblo. También el Frente Nacionalista Patria y Libertad considera esenciales la disciplina social y la responsabilidad colectiva, como medio para la organización de la comunidad sin discriminaciones, el abandono de la demagogia y el logro de la justicia social. 
Las actitudes autoritarias, la adhesión al principio de ley y orden, así como la hostilidad ante las infracciones de las normas, se hallan expresamente formuladas en los discursos de Patria y Libertad y en las concepciones de Patria Nueva Sociedad. El Manifiesto Nacionalista de Patria y Libertad afirma explícitamente la vocación de "restablecer el orden y el imperio de la ley" (1971, p. 8); además, lamenta la incapacidad de algunos gobiernos para sancionar a los infractores de la ley, y considera prioritario disponer de un gobierno autoritario que no dude en castigar al infractor, así como garantizar una justicia legal que permita "reparar o sancionar el quebrantamiento de la ley, efectiva y oportunamente" (p. 15). Por su parte, Patria Nueva Sociedad considera que la legislación penal debe procurar la efectiva expiación de la culpa y la protección del pueblo contra aquello que impugne su conciencia de justicia natural; por eso, argumenta que "el daño a la vida, a la salud, al patrimonio, a la cultura y a los fundamentos de la vida en sociedad, deben ser castigados con el máximo rigor de la Ley" (concepto 50).

La idea de que la realidad social encierra conflictos violentos, competencia y luchas por el poder también se hace presente en los discursos de las formaciones chilenas de ultraderecha. El discurso del Movimiento Nacional Socialista justifica explícitamente el recurso a la violencia cuando no resultan suficientes las razones; de hecho, el nacismo se autodescribe como una fuerza física "que a la violencia no trepidará en responder con la violencia” (1932, p. 17). Del mismo modo, el Movimiento Revolucionario Nacional Sindicalista se presenta como una organización en lucha e involucrada en la conquista del poder mediante la acción directa; por eso, defiende la utilización estratégica de la vía armada y el derecho a rebelión en circunstancias de opresión o

Tabla 1.

Expresión de actitudes de autoritarismo de derecha y de orientación a la dominación social en algunos partidos de la extrema derecha chilena.

\begin{tabular}{|c|c|c|c|c|}
\hline & $\begin{array}{c}\text { Movimiento } \\
\text { Nacional Socialista }\end{array}$ & $\begin{array}{c}\text { Movimiento } \\
\text { Revolucionario } \\
\text { Nacional } \\
\text { Sindicalista }\end{array}$ & $\begin{array}{c}\text { Frente Nacionalista } \\
\text { Patria y Libertad }\end{array}$ & $\begin{array}{c}\text { Patria Nueva } \\
\text { Sociedad }\end{array}$ \\
\hline Tradicionalismo & & + & + & + \\
\hline $\begin{array}{l}\text { Principio de } \\
\text { autoridad }\end{array}$ & & & + & + \\
\hline $\begin{array}{l}\text { Disciplina y } \\
\text { responsabilidad }\end{array}$ & + & & + & + \\
\hline $\begin{array}{l}\text { Jerarquía y Subor- } \\
\text { dinación individual }\end{array}$ & + & + & & + \\
\hline $\begin{array}{l}\text { Principio de ley y } \\
\text { orden }\end{array}$ & & & + & + \\
\hline Rigor sancionador & & & + & + \\
\hline $\begin{array}{l}\text { Justificación de la } \\
\text { lucha violenta }\end{array}$ & + & + & + & \\
\hline
\end{tabular}


represión políticas. En cuanto al Frente Patria y Libertad, se autocaracteriza como una posición de vanguardia en la lucha contra el marxismo, e invita a los chilenos a combatir en esta "cruzada" (1971, p. 32), que no dudará en servirse de los medios de la lucha armada revolucionaria o apoyar un pronunciamiento de las fuerzas armadas. Solo la cosmovisión de Patria Nueva Sociedad rechaza y condena abiertamente "toda forma de violencia, violación de los Derechos Humanos y de la Naturaleza como formas de acción política" (concepto 69).

En suma, las actitudes ideológicas vinculadas al autoritarismo de derechas y a la orientación a la dominación social se expresan y articulan de manera explícita y variable en los discursos de la extrema derecha chilena, como se aprecia en la tabla 1.

\section{Marcos figurativos}

Desde los años treinta, los críticos del fascismo llamaron la atención sobre su tendencia a la mistificación naturalista de la situación sociohistórica como una totalidad orgánica auténtica y una realidad natural eterna. Las primeras reflexiones sobre la personalidad autoritaria de los fascistas ya destacaban cómo el doble impuso de dominación y de sumisión ante un poder omnipotente involucraba cierta invocación de una naturaleza providencial e inevitable; por ejemplo, en la retórica hitleriana se expresa constantemente el sometimiento a una naturaleza tremenda, la naturalización de la crueldad y la afirmación de un crudo darwinismo social que consagra el instinto de autoconservación, la lucha por la supervivencia y la dominación del débil (Fromm, 2006, cap. 6). En efecto, la naturalización y cosificación organicista de la condición histórica constituiría uno de los elementos decisivos de la ideología fascista y la fuente de algunos de sus mitos políticos fundamentales: el mito de autoctonía que mistifica la natural comunidad orgánica del pueblo sustentada en la tierra y la sangre; la consagración de las diferencias raciales y la selección de las razas en nombre de la fortaleza y salud de las especies; la concepción biologicista de la vida y la evolución de la humanidad, así como la exaltación mítica del cuerpo; o bien el culto de la maternidad, de la sexualidad reproductiva y del engendramiento numeroso (Lukacs, 1975, p. 35; Marcuse, 1969, pp. 30-36; Reich, 1972, pp. 101-102).

Los discursos de la extrema derecha chilena también aparecen investidos bajo cierto marco figurativo naturalista y organicista, que tan pronto resalta la vitalidad dinámica de las fuerzas históricas como destaca las funciones orgánicas de las comunidades humanas; tan pronto enfatiza la pluralidad de los cuerpos sociales o las formas de vida como remarca la integración orgánica de la vida en común. En el caso del manifiesto del Movimiento Nacional Socialista, el léxico de la fuerza proporciona un trasfondo figurativo para cierta representación dinámica de la actividad política e histórica; bajo ese marco dinámico, la trama de la realidad social consistiría en un juego de fuerzas activas y creadoras, ya se trate de fuerzas naturales, espirituales, morales o políticas. El nacismo chileno vincula además esa trama dinámica con cierto enmarcado vitalista de la actividad política e histórica: las naciones, las instituciones y las fuerzas socio-históricas exhiben mayor o menor vitalidad e instinto de conservación, y la apuesta del nacional socialismo consiste "en crear una fuerza 
civil, pletórica de vida, de la que habrá de surgir una nueva concepción del Estado, en armonía con las tendencias sociales, económicas y espirituales del siglo" (1932, p. 16). Por eso, el nacismo chileno de los años treinta consideraba que los partidos políticos tradicionales no eran más que cadáveres que habrían fallecido con la etapa histórica liberal que los engendró, sin que quepa resurrección posible de un pasado "condenado, fatalmente, a morir" (p. 12). Por otra parte, la retórica nacionalsocialista chilena vincula el mantenimiento de la vitalidad de las actividades e instituciones sociales al sano cumplimiento de su función, y justifica la subordinación del individuo a la voluntad de la Comunidad del Pueblo, en términos de cierto vocabulario de la función social.

En los discursos del Movimiento Revolucionario Nacional Sindicalista, la actividad humana e histórica se concibe bajo el signo de la trascendencia cultural y ética, pero la naturalización de la esencia humana y de la convivencia comunitaria se lleva a cabo en el marco de todo un léxico funcional y bajo la premisa de que "las funciones generan organismos que son expresión de actividades connaturales al hombre" (1969, proposición 22). En ese enmarcado funcional de la vida social, la función cultural, económica, religiosa, defensiva o política se realizarían en sus respectivas comunidades, orgánicamente integradas en el Estado de Comunidad Nacional, que institucionaliza el convivir comunitario y la organización de las tareas humanas y organismos sociales. En sus textos digitales, el Movimiento Revolucionario Nacional Sindicalista caracteriza como cuerpos sociales a las unidades orgánicas de la comunidad nacional que cumplen funciones y generan organismos comunitarios. De ese modo, el enmarcado organicista faculta el reconocimiento de ciertas funciones permanentes e intransferibles connaturales a la actividad humana y la convivencia nacional; se trata de una investidura figurativa idónea para sustentar la ideología del corporativismo político, tan cara a ciertos sectores de la extrema derecha chilena.

El manifiesto del Frente Nacionalista Patria y Libertad no es ajeno al léxico organicista y funcional característico del corporativismo. No en vano, el texto introduce significantes claves con una marcada resonancia corporativista, y asocia la auténtica participación y convivencia democráticas a una democracia corporativa y a una democracia funcional, capaces de incorporar plenamente la actividad social. Asimismo, el léxico de la integración, esto es, la apelación a un Estado Integrador y una Empresa integrada, proporciona un marco para armonizar la convivencia nacional y la colaboración productiva. Sintomáticamente, las metáforas patológicas conviven con las organológicas en una formación que se autoconcibe como vanguardia contrarrevolucionaria: el sistema y el gobierno establecido aparecen figurativamente enmarcados como gusanos o un cáncer que carcomen toda la organización social.

Sin embargo, la ultraderecha New Age, que representa Patria Nueva Sociedad, es la que hace explícito el enmarcado naturalista y orgánico de la actividad social y la praxis política. De hecho, el Socialismo Nacional de Patria Nueva Sociedad se presenta como una cosmovisión natural, arraigada en la comprensión de la naturaleza y expresión de toda una ecología de la mente y de la 
actividad humana. El fundamento natural de semejante Socialismo Nacional no es otro que "el sostenimiento de la Vida en todas sus manifestaciones" (2003, concepto 8), de manera que la concepción del ser humano solo resulta posible en el marco de la Naturaleza y como "uno más de los organismos de la comunidad de Vida del Planeta" (concepto 10). La praxis social y política son consecuentemente enmarcadas como un asunto de adaptación de las comunidades a sus territorios y de evolución biológica, pero también de preservación de la biodiversidad y mantenimiento de la sustentabilidad ecológica. En ese sentido, la cosmovisión del Socialismo nacional privilegia la conservación del ciclo de la naturaleza sobre cualquier proyecto de desarrollo lineal que amenace la vida de los pueblos y a las generaciones futuras. Patria Nueva Sociedad naturaliza su Socialismo como expresión del altruismo espontáneo de la vida y promoción de cierta homeostasis y sinergia sociales. Como ocurre en las otras formaciones de extrema derecha chilenas, la naturalización de la praxis y la institución política se concentra en el significante nación; en ese sentido, Patria Nueva Sociedad explicita el mito político de autoctonía natural del nacionalismo, conforme al cual "la Nación es natural, el Estado es artificial" (concepto 29). Para concebir una institucionalidad política que preserve la vida de la Nación, el Socialismo nacional defiende un Estado orgánico "en continua evolución y permanente adaptación a las necesidades y desarrollo de la Nación" (concepto 32), que funcionaría como el cuerpo obediente ante los propósitos de la mente nacional. Para resultar legítimos, también el derecho y la justicia resultan orgánicamente naturalizados y tienen que arraigar en la Naturaleza de la Comunidad del Pueblo. La concepción política de Patria Nueva y Sociedad se encuadra abiertamente en un modelo corporativo, que integra orgánicamente "la totalidad de las organizaciones que representan a los cuerpos sociales, agrupadas según su naturaleza, función, servicios y objetivos a nivel nacional" (concepto 62). En suma, el Socialismo Nacional se enmarca explícitamente como una auténtica ecología política al servicio de la sustentabilidad de las naciones, del equilibrio planetario de las comunidades y de la creación de una nueva Civilización basada en las leyes de la Vida y la Naturaleza.

\section{Construcciones ARgumentativas}

A pesar de sus arrebatos apasionados y exclamaciones beligerantes, los discursos de la extrema derecha chilena no son la expresión inmediata y cruda de algún irracionalismo político, sino que encierran pretensiones de validez acorazadas tras una lógica aparentemente férrea. En el razonamiento ideológico de los movimientos de extrema derecha chilenos encontramos, pues, esa coacción lógica que - según Hannah Arendt (1974, pp. 569-570) - resulta característica de ciertas ideologías contemporáneas, en tanto que lógicas de las ideas, deducciones concluyentes y explicaciones absolutas a partir de alguna idea convertida en premisa. De hecho, la premisa ultraderechista que contiene el despliegue de toda deducción lógica y de toda explicación no es otra que el principio de identidad lógica, erigido en tautología identitaria: la comunidad es la comunidad, el pueblo es el pueblo, la raza es la raza y la nación es la nación. Semejante premisa identitaria concentra todo 
el movimiento lógico y el discurso explicativo de una extrema derecha que naturaliza y consagra la expresión de lo propio, la autenticidad identitaria y la autorreferencia de toda pertenencia comunitaria e identidad cultural, al mismo tiempo que excluye la intromisión externa, el influjo foráneo y las ideas extranjeras. Como premisa, la tautología de la identidad implica toda esa lógica identitaria de conjuntos que Castoriadis (1989, pp. 22-34) caracterizó como la determinación exhaustiva de relaciones entre los distintos elementos de un conjunto definido; de esa manera, cada elemento y cada individuo pueden ser adscritos e identificados como contenidos de algún conjunto, $\mathrm{y}$, bajo esta lógica identitaria conjuntista, se esbozaría un sistema social completo, compuesto como una jerarquía estáticamente articulada de conjuntos o subsistemas. El discurso de la pertenencia comunitaria y el léxico organicista de los cuerpos sociales expresan nítidamente esa lógica identitaria conjuntista en los textos de la extrema derecha chilena.

En la extrema derecha chilena existen distintas modulaciones de la premisa tautológica de la identidad y de su lógica identitaria conjuntista, según el modo en que se especifican las relaciones que definen las pertenencias de conjunto: la autoexpresión genuina de lo propio, la autorreferencia inmanente del conjunto e, incluso, la copertenencia de medios y fines, o bien de problemas y soluciones. En el Movimiento Nacional Socialista Chileno de los años treinta, ya se hallaba presente la premisa identitaria y la lógica conjuntista, en la medida en que el nacismo se definía como un movimiento nacional capaz de activar el orgullo de pertenencia racial, armonizar las partes, incluir a todos los elementos sociales y definir las funciones sociales que integran el conjunto de la vida colectiva. Bajo la premisa identitaria de tratarse de un movimiento concerniente al conjunto nacional, los nacionalsocialistas chilenos comprometían autorreferencialmente consagrarse como chilenos en nombre de Chile para la grandeza de Chile. De modo análogo, el Movimiento Revolucionario Nacional Sindicalista caracteriza la cultura en términos identitarios, como "la expresión de la autenticidad de un pueblo en el enfrentamiento consigo mismo, la sociedad, la historia y el universo todo" (1969, proposición 6). Además, la doctrina nacionalsindicalista concibe la revolución como un reencuentro con los valores propios y una consumación de la comunidad nacional de los chilenos, y promueve un Estado de Comunidad Nacional en que las distintas funciones sociales se asocian a organismos definidos y cuerpos sociales acotados, de modo que las actividades humanas se organizan como funciones del conjunto de la nación y de la convivencia de las comunidades. El Frente Patria y Libertad lleva la premisa identitaria hasta el paroxismo, en la medida en que considera que Chile, como cualquier otro país, tiene que inspirarse en su propia realidad y rechazar la injerencia externa o la influencia foránea. Desde ese punto de vista, el nacionalismo sería una ideología propia de cada país que afirma su peculiaridad identitaria, se inspira en el amor a la patria y en las propias tradiciones, y trata de dar una respuesta nacional a los problemas nacionales. El nacionalismo que defiende el Frente Patria y Libertad sería un desarrollo de la tautología identitaria en forma de ideología práctica: "una respuesta chilena a los problemas chilenos" (1971, p. 9). Pero, para consumar 
esa autorreferencia identitaria, Patria y Libertad requiere de una concepción integradora del Estado y de la empresa, así como de la democracia funcional, de modo que todos los elementos chilenos puedan participar en el conjunto de la decisión política y la producción social. Por último, también el discurso de Patria Nueva Sociedad responde a la lógica identitaria y desarrolla la premisa tautológica de la identidad, aunque su concepción de los conjuntos sociales y de la jerarquía de los sistemas y subsistemas alcanza un rango planetario y ecológico. En ese sentido, el Socialismo Nacional de Patria Nueva Sociedad concilia la visión identitaria de las pertenencias, las solidaridades y las expresiones auténticas de lo propio, con una visión pluralista, orgánica y corporativa de los conjuntos sociales e institucionales (esto es, las Comunidades de los Pueblos y sus ordenaciones políticas), ecológicamente incluidos en el sistema de sistemas de la Naturaleza. En suma, bajo la premisa tautológica de la identidad, la extrema derecha chilena desarrolla implacablemente las implicaciones lógicas de la relación de pertenencia, de la expresión de lo propio y de la inclusión de las partes, como si existiera una distribución fija de los elementos en relaciones determinadas y en conjuntos definidos.

En la arquitectura lógica de los discursos de la extrema derecha chilena, cabe reconocer cierta estrategia argumentativa de polarización tajante de las opciones y división excluyente de los términos, que podríamos designar como dilematización. Al presentar la situación social e histórica como una encrucijada de caminos divergentes, se inviste como un dilema lógico cierta codificación ideológica del escenario político, y se fuerza una percepción dicotómica de la situación. Puesto que uno de los cuernos del dilema aparece marcado negativamente, la estrategia argumentativa de la dilematización refuerza la conclusión lógica de que la vía correcta es la propuesta defendida por la parte que argumenta, sin que resulten concebibles otras opciones. Por ejemplo, el Movimiento Nacional Socialista de los años treinta describía una encrucijada fatal en que estaría comprometido el provenir histórico de Chile: o bien se seguía el camino agotado de la democracia liberal, del liberalismo económico y político, así como del constitucionalismo y el régimen parlamentario, que nos arrastraría por la pendiente de las revueltas, la anarquía y las aventuras caudillistas; o bien se apostaba por el camino escarpado y riguroso en que una nueva fuerza política regenere la vitalidad de la nación, rescate el orgullo de raza y encauce el destino colectivo, como pretendía el Movimiento Nacional Socialista. El dilema es tan aparente como obvia es la conclusión inducida: la vía correcta es la del extremo nacionalsocialista. En el Movimiento Revolucionario Nacional Sindicalista, encontramos algunos ejercicios semejantes de dilematización: se nos hace elegir entre el reformismo que solo reajusta el aparataje del Estado, reducido a la fórmula de la democracia liberal, de manera instrumental a la dominación plutocrática, $\mathrm{y}$, por otra parte, el ser revolucionario, que pretende conquistar el poder y crear una nueva forma de vida, sustentada en la trascendencia, la jerarquía y la plena realización de lo humano. El Frente Patria y Libertad utilizó profusamente los dilemas aparentes para forzar cierta representación de la situación política entre los años sesenta y comienzos de los setenta. El principal ejercicio de dilematización de 
Patria y Libertad consistió en contraponer rígidamente dos vías para modernizar la vida política y responder a la crisis de la democracia liberal: el marxismo, basado en una ideología foránea y totalitaria, en la democracia popular y el capitalismo de Estado; o bien el nacionalismo, sustentado ideológicamente en la propia realidad chilena, y promotor de la democracia y empresa integradas. Para Patria y Libertad, el nacionalismo era "el único camino de quienes aspiran a frenar al totalitarismo prosoviético, superando nuestros problemas y encarando resueltamente nuestras debilidades y defectos" (p. 10). Pese a su pretensión de aportar una cosmovisión comprehensiva, el discurso de Patria Nueva Sociedad no elude la representación polarizada de las opciones sociales y políticas; incluso las amplifica a escala planetaria como un dilema cósmico concerniente a la vida misma de la Naturaleza: por un lado, está el camino del nuevo orden mundial, del dominio del mercado trasnacional capitalista, de la mercantilización global de todas las formas de vida, del consumismo, el materialismo productivista y el nihilismo; por otro lado, aparece la vía de quienes expresan auténticamente las tradiciones, cultura y estirpe de la Comunidad del Pueblo, y quienes luchan por forjar una nueva Civilización planetaria acorde a la ecología del espíritu y del equilibrio de la Naturaleza. En ese sentido, los argumentos del extremismo de derecha se sirven constantemente de la retórica de los extremos y de la estrategia de la dilematización.

Aunque el pensamiento político de la extrema derecha chilena se pliega a la premisa identitaria y fuerza la dilematización de la situación histórico-social, no puede decirse que su lógica respete exactamente el principio del tercio excluido. En efecto, las formaciones de la extrema derecha chilena suelen definir su posición como una tercera vía que excluye los polos opuestos del espacio político (izquierda y derecha, capitalismo y marxismo, democracia liberal y democracia popular, etc.) $\mathrm{y}$, en un gesto hiperbólico de superación, las trasciende en una forma de vida y una organización institucional más lograda y más allá de las oposiciones convencionales. Por ejemplo, el Nacional Socialismo chileno se autodescribe como un movimiento que no se identifica con el tradicional sistema de partidos de la democracia liberal ni con el marxismo internacional; se opone igualmente a la plutocracia asociada al liberalismo económico y al materialismo económico del "comunismo moscovita" (p. 21). De ese modo, el Nacional Socialismo a la chilena prometía trascender una situación histórica superada, mediante el enérgico movimiento disciplinado de una nueva fuerza espiritual. Por su parte, el Movimiento Revolucionario Nacional Sindicalista apuesta más explícitamente por la trascendencia revolucionaria creadora de cultura y de valores, más allá de la opción entre el régimen demo-liberal imperante y su alternativa marxista, en virtud de un Estilo ético en abierta oposición anti-partidista. También el Frente Nacionalista Patria y Libertad se presenta como una vanguardia en oposición al marxismo totalitario y a la democracia partidista. Abiertamente, el Nacionalismo de Patria y Libertad se posiciona como una ideología que no es ni de derechas ni de izquierdas, y se sitúa más allá de la democracia liberal y la democracia popular; el nacionalismo trascendería ambas opciones mediante una organización de avanzada auténticamente democrática y libertaria, que compartiría 
con la izquierda la identificación con los explotados y recogería de la derecha el principio de la ley y el orden. Por último, Patria Nueva Sociedad participa de esta retórica de la superación, al presentarse como una cosmovisión más allá del marxismo y del capitalismo, más allá del igualitarismo liberal y del colectivismo marxista, más allá del estatismo marxista y el "enanismo estatal" (2003, concepto 35) capitalista y, en definitiva, más allá de la izquierda y la derecha políticas tradicionales. La puja por rebasar las posiciones políticas superadas lleva a Patria Nueva Sociedad a apostar por una forma de trascendencia que, más que solo política o económica, alcanza dimensiones planetarias y ecológicas, pues se trata de las "leyes trascendentes del Espíritu, de la Vida y de la Naturaleza" (concepto 110) que debieran inspirar una Civilización superior.

En suma, la arquitectura lógica del pensamiento de la extrema derecha chilena despliega tensiones argumentativas que parecen seguirse consecuentemente del rigor de sus premisas identitarias, de sus dilemas excluyentes, de sus pretensiones de trascendencia absoluta y, en el fondo, de toda la retórica de lo extremo que se esboza en su discurso. Estas tensiones se agudizan cuando la premisa tautológica de la identidad de lo propio, la dilematización forzada de las opciones políticas y la seudotrascendencia de todas las oposiciones tradicionales se sitúan sobre el trasfondo de todo un marco figurativo naturalista y organicista, que cosifica la praxis social y las realizaciones institucionales humanas. De esta particular lógica de la ultraderecha chilena, cabría sostener que - como Simone de Beauvoir afirmaba del pensamiento político de la derecha, en general - induce una síntesis no dialéctica del realismo, la dureza, el pesimismo e, incluso, el cinismo en la naturalización de lo dado $y$, por otra parte, de cierto espiritualismo grandilocuente y fe indefinida en la trascendencia. En ese sentido, la retórica de lo extremo de la ultraderecha chilena no es sino el despliegue de las propias tensiones lógicas sin resolver derivadas de su marco naturalista, sus tautologías identitarias, sus dilemas aparentes y sus envites de seudotrascendencia total.

\section{CONCLUSIÓN: LA \\ ULTRADERECHA EN EL PODER}

Como parte de la labor de desconexión de la derecha chilena tradicional con respecto a los movimientos de ultraderecha, tampoco se suelen reconocer los vínculos ideológicos que atan a la Dictadura Militar con el pensamiento de la extrema derecha. Aunque algunos observadores contemporáneos no dudaron en asociar a la derecha golpista $\mathrm{y}$ al régimen militar con una forma de fascismo (Carmona, 1973; Ramírez Necochea, 1978), se ha vuelto frecuente la designación de la dictadura militar como un tipo de Estado burocrático autoritario, básicamente caracterizado como una institucionalidad comandada por la Fuerzas Armadas y las grandes empresas. Se trataría de un tipo de aparato estatal al servicio de la alta burguesía trasnacionalizada, abocado a implantar represivamente el orden social, subordinar y excluir a los sectores populares, suprimir la participación democrática y la representación popular, despolitizar los problemas sociales bajo la apariencia de una racionalidad técnica, normalizar la economía y garantizar la acumulación capitalista (O'Donnell, 1982, pp. 60-62). Sin embargo, a pesar 
de la despolitización tecnocrática del régimen militar, cabe reconocer en su discurso ideológico la presencia de los temas típicos de la extrema derecha chilena.

En efecto, la Declaración de principios de la Junta Militar apela a propósitos característicos de los movimientos chilenos de ultraderecha, como la defensa de la propia tradición histórica e identidad cultural de la nación chilena, la consagración de valores fundamentales del alma chilena, el gobierno autoritario, el ejercicio riguroso del principio de autoridad, la sanción drástica de la indisciplina, la promoción del corporativismo y el gremialismo, la implantación de un estilo moral basado en el esfuerzo y la competencia, así como la despolitización de la vida colectiva y de la institucionalidad política. Si analizamos el discurso de la Declaración de Principios de la Junta Militar (publicada por el régimen en 1974 y escrita por uno de los principales ideólogos del corporativismo chileno -y ex-militante de Patria y Libertad - Jaime Guzmán), resulta patente la presencia de la premisa identitaria y la inspiración nacionalista; también se manifiesta la dilematización excluyente que contrapone el modelo marxista y el de las sociedades desarrolladas de Occidente; por último, la propuesta de reconstrucción nacional bajo el régimen militar se presenta como una misión histórica trascendente que superará las contradicciones heredadas y abrirá una nueva etapa en el destino nacional, más allá del individualismo liberal y del colectivismo, y más allá del materialismo de las sociedades de consumo y del totalitarismo marxista. La Declaración de la Junta Militar también comparte el imaginario naturalizado y organicista de la extrema derecha: el lenguaje de los cuerpos intermedios y de las funciones sociales inherentes va de la mano con la referencia a las formas naturales y a la naturaleza humana. La pieza fundamental de la concepción política de la Junta Militar la proporciona el léxico de la subsidiariedad, que integra el reconocimiento corporativista de los cuerpos intermedios y, por otra parte, la valoración de la autonomía de los agentes económicos, para que puedan desarrollar su iniciativa individual y garantizar su propiedad privada sin interferencia estatal alguna. Bajo el principio de subsidiaridad, "ninguna sociedad superior puede arrogarse el campo que respecto de su propio fin específico pueden satisfacer las entidades menores" ("Concepción del hombre y de la sociedad", punto 4, párrafo 3), de modo que el Estado solo ha de asumir o subsidiar aquellas funciones que los cuerpos intermedios no puedan desempeñar. En suma, con todo su marco asociado organicista y funcional, el léxico de la subsidiaridad legitima tanto la libre empresa como la conservación de los cuerpos sociales tradicionales, y limita tanto la intervención estatal cuanto la participación democrática.

Desde esa perspectiva, la novedad ideológica de la Junta Militar radica en la combinación calibrada de motivos nacionalistas, corporativistas y neoliberales en un solo entramado discursivo, al mismo tiempo que la propuesta se presenta como una planificación técnica y un proyecto nacional ajeno a todo mesianismo ideológico. $Y$ es que, más que como una ideología, el nacionalismo neoliberal y corporativista se autoconcibe como un estilo ético y pragmático de conducción política. En ese sentido, el discurso de la Junta Militar se sitúa en el centro de la constelación ideológica de la ultraderecha 
chilena, pero consigue articular su propuesta bajo una apariencia despolitizada y desideologizada. Bajo esa forma técnica, pragmática y despolitizada, el discurso de la ultraderecha chilena se reprodujo en el diseño institucional que sigue vigente hasta el día de hoy. Si en otras latitudes las formaciones de extrema derecha y las políticas ultranacionalistas han ganado presencia en el ruedo político, en Chile no parece necesario, pues el discurso de la ultraderecha permea el marco institucional y el modelo gubernamental, así como se decanta en los partidos políticos herederos del pinochetismo y, quizá, se ha filtrado incluso en el nacionalismo banal y el autoritarismo cotidiano.

\section{REFERENCIAS}

Adorno, T. W., Frenkel-Brunswik, E., Levinson, D. J., Nevitt Sanford, R. (2006). La Personalidad Autoritaria (Prefacio, Introducción y Conclusiones). Empiria. Revista de Metodología de las Ciencias Sociales, 12, 155-200.

Altemeyer, B. (1993). Nacionalismo y autoritarismo de derechas entre legisladores americanos. Psicología Política, 7, 7-18.

Arendt, H. (1974). Los orígenes del totalitarismo. Madrid: Taurus.

Betz, H. G. (1993). The New Politics of Resentment: Radical Right-Wing Populist Parties in Western Europe. Comparative Politics, 25 (4), 413-427.

Bobbio, N. (1995). Derecha e Izquierda. Razones y significados de una distinción política. Madrid: Taurus.

Bohoslavsky, E. (2012). ¿Qué es lo nuevo de la nueva derecha en Chile? Anticomunismo, corporativismo y neoliberalismo, 1964-1973. História Unisinos, 16 (1), 5-14.
Ley de principios del movimiento nacional de 1958. Boletín Oficial del Estado (BOE), 95, España, 21 de abril de1967, pp. 5251-5252. Recuperado de https:// www.boe.es/boe/dias/1967/04/21/pdfs/ A05250-05272.pdf

Carmona de la Peña, F. (1973). El fascismo chileno, lección para Latinoamérica. Problemas del desarrollo, 4 (16), 69-108.

Castoriadis, C. (1989). La institución imaginaria de la sociedad. Vol. 2. El imaginario social y la institución. Barcelona: Tusquets.

Correa Sutil, S. (1989). La derecha en Chile contemporáneo: la pérdida del control estatal. Revista Ciencia Política, 11 (1), 5-19.

Correa Sutil, S. (2005). Con las riendas del poder. La derecha chilena en el siglo XX. Santiago de Chile: Sudamericana.

Cristi, R., y Ruiz, C. (1992). El pensamiento conservador en Chile. Santiago de Chile: Editorial Universitaria.

De Benoist, A., y Champetier, C. (2000) Manifiesto: la Nueva Derecha del año 2000. Recuperado de https://archive.org/details/ ManifiestoLaNuevaDerechaDelAno2000

De Beauvoir, S. (1969). El pensamiento político de la derecha. Buenos Aires: Siglo Veinte.

Duckitt, J., Bizumic, B., Krauss, S. W., y Heled, E. (2010) A Tripartite Approach to Right-Wing Authoritarianism: The Authoritarianism-Conservatism-Traditionalism Model. Political Psychology, 31 (5), 685-715.

Duckitt, J, y Sibley, C. G. (2009). A Dual-Process Motivational Model of Ideology, Politics, and Prejudice. Psychological Inquiry, 20, 98-109

Etchepare, J. A., y Stewart, H. I. (1995). Nazism in Chile: A Particular Type of 
Fascism in South America. Journal of Contemporary History, 30, 577-605.

Falange Española de las J. O. N. S. (30 de noviembre de 1934). El programa de Falange Española de las J. O. N. S. $A B C$, pp. 32-34. Recuperado de http://hemeroteca.abc.es/nav/Navigate.exe/hemeroteca/madrid/abc/1934/11/30/032.html

Fromm, E. (2006). El miedo a la libertad. Barcelona: Paidós.

Lukacs, G. (1975). La crisis de la filosofía burguesa. Buenos Aires: La Pléyade.

Mann, M. (2004). Fascists. New York: Cambridge University Press.

Marcuse, H. (1969). La lucha contra el liberalismo en la concepción totalitaria del estado. En Cultura y sociedad (pp. 13-44). Buenos Aires: Sur.

Movimiento Nacional Socialista. (1932). El Movimiento Nacional Socialista de Chile. Santiago de Chile: Imprenta "La Tracción".

Movimiento Revolucionario Nacional Sindicalista. (1969). Proposiciones políticas a las comunidades de la nación. Forja, 6 , 6-8.

Movimiento Revolucionario Nacional Sindicalista. (2017). MRNS. Recuperado de http://www.mrns.cl/w3/

Mudde, C. (2007). The ideology of the extreme right. New York: Manchester University Press.

Muis, J., e Immerzeel, T. (2016). Radical Right Populism. Sociopedia.isa (e-journal). DOI: $10.1177 / 2056846016121$

Mussolini, B. (2015). La doctrina del fascismo. Editorial kamerad. (Obra original publicada en 1937). Recuperado de https://editorialkamerad.files.wordpress. com/2014/08/la-doctrina-del-fascismo1. $\mathrm{pdf}$
NSDAP. (2015). Los 25 puntos del partido nacionalsocialista alemán de los trabajadores. Editorial Kamerad. (Obra original publicada en 1920). Recuperado de https://editorialkamerad.files.wordpress. com/2014/09/los-25-puntos.pdf

O’Donnell, Guillermo (1982). El Estado Burocrático Autoritario. Buenos Aires: Editorial de Belgrano.

Patria Nueva Sociedad (2003). Ciento once conceptos para comprender el Socialismo Nacional. Recuperado de http://vans. mforos.com/193893/1173633-111-conceptos-para-comprender-el-socialismo-nacional/

Ramírez Necochea, H. (1978). El fascismo en la evolución política de Chile. Araucaria, 1, 9-33.

Reich, W. (1972). Psicología de masas del fascismo. Madrid: Ayuso.

Rodríguez Araujo, O. (2004). Derechas y ultraderechas en el mundo. México, D.F.: Siglo XXI.

Rodríguez Grez, P. (1971). Manifiesto nacionalista: Frente Nacional Patria y Libertad. Santiago de Chile: Sopech.

Scully, T. (1996). La reconstitución de la política de partidos en Chile. En S. Mainwaring y T. Scully (Eds.), La construcción de instituciones democráticas: Sistemas de partidos en América Latina (pp. 83-112). Santiago de Chile: CIEPLAN.

Sidanius, J., y Pratto, F. (1999). Social dominance: an intergroup theory of social hierarchy and oppression. Cambridge: Cambridge University Press.

Van Dijk, T. (2006). Ideología. Una aproximación multidisciplinaria. Barcelona: Gedisa. 